\section{Internuclear Distance and Vibration Frequency for Diatomic Molecules}

THF equilibrium internuclear distance $r_{\ell}$ and the vibration frequency $\omega_{e}$ for diatomic molecules were connected by Morse in the formula $\omega_{e} r_{e}{ }^{3}=$ const. $=$ $3 \cdot 000 \times 10^{-21} \mathrm{~cm}^{2}$ for many molecules. This, however, does not hold accurately, and in fact the constant shows a periodic error. Douglas Clark has proposed a modified formula, $\omega_{e} r_{e}{ }^{3} \sqrt{ } n=$ const., where $n$ is the 'group number', and is the number of 'shared electrons', usually the sum of the valency electrons in the atoms composing the molecule. This constant varies for each molecular period, and appears to be quite arbitrary. Neither of these formulæ is capable of fitting the case of isotopes, for which $r_{\varepsilon}$ has the same value, while $\omega_{e}$ depends on the reduced mass.

We have considered a formula involving the reduced mass $\mu$, namely, $\omega_{e} r_{e}^{3} \sqrt{ } \mu=$ const., and examined it with relation to experimental data for non-hydride molecules. Using Clark's nomenclature, it is found that for the molecular periods $K K, K L$ and $K M$ which he discussed, the agreement is very nearly as good as with his formula and almost certain to be within the limits of observational error. In addition, it gives identical constants for the isotopes $\mathrm{B}^{10} \mathrm{O}$ and $\mathrm{B}^{11} \mathrm{O}$, and for $\mathrm{H}_{2}$ and $\mathrm{HD}$.

The formula also gives consistent results for the $L L$ and $M M$ periods, and it is found that the constant for the $K L$ period is the mean of the constants for the $K K$ and $L L$ periods, and that for $K M$ the mean of $K K$ and $M M$. Finally, the constant for each period is no longer arbitrary, but is approximately proportional to the number of completed electronic shells in the molecule, the value for the $K K$ period being $10.6 \times 10^{-33} \mathrm{gm} . \frac{1}{2} \mathrm{~cm} .{ }^{2}$.

We hope to publish a fuller account of this work shortly.

\section{H. S. ALLEN}

A. K. Longair.

Physical Laboratory,

University,

St. Andrews.

March 20.

\section{Raman Spectra of some Deuterium Compounds}

UsING a high intensity glass spectrograph with a dispersion of $15 \mathrm{~A}$. per $\mathrm{mm}$. we have measured the Raman frequencies of tetrachlordeuterium-ethane and cis-trans deuterium-dichlorethylene prepared from heavy water. The results are briefly given below, together with mean values of the Raman frequencies $\left(\mathrm{cm}^{-1}\right)$ of the corresponding light hydrogen compounds taken from earlier measurements ${ }^{1}$ for comparison. Intensities are given in brackets.

$\mathrm{C}_{2} \mathrm{D}_{2} \mathrm{Cl}_{4}: 174(4), 240(3), 287(4), 352(8), 399(1), 532(2), 629(6), 701(2)$, 739(5), $947(3), 2240(6)$

$\mathrm{C}_{2} \mathrm{H}_{2} \mathrm{Cl}_{4}: 171(4), 236(6), 286(4), 351(5), 395(2), 544(2), 644(4), 761(2)$, $802(5), 1212(2), 2984(6)$

$\mathrm{C}_{2} \mathrm{D}_{2} \mathrm{Cl}_{2}(c i s): 176(6), 368(3), 515\left(1 \frac{1}{2}\right), 689(6), \quad 850(3)$, $\mathrm{C}_{2} \mathrm{H}_{2} \mathrm{Cl}_{2}$ (cis): $1570(6), 1507(2), 2325(6)$.

$\mathrm{C}_{2} \mathrm{H}_{2} \mathrm{Cl}_{2}$ (cis): $173(6), 406(4), 565(2), \quad 714(5), 806(1), 878\left(\frac{1}{2}\right), 1182(4)$, $\mathrm{C}_{3} \mathrm{D}_{2} \mathrm{Cl}_{2}$ (trans) : $346(4), 657(1), \quad 759(2), \quad 992(6), \quad 1570(6), \quad 1547(3)$, $\mathrm{C}_{2} \mathrm{H}_{2} \mathrm{Cl}_{8}$ (trans) : $351(7), \quad 763(2), 846(3), 1271(5), 1578\left(3 \frac{1}{2}\right), 1625\left(\frac{1}{4}\right)$, $1694\left(\frac{1}{2}\right), 3077(4)$.

The isotope effect is in many cases clearly deter. minative and indicates the participation of the hydrogens in the different oscillations. Thus the alteration of the $\mathrm{C}-\mathrm{H}$ frequency is specially strong; in tetrachlorethane, for example, we have:

$$
\begin{aligned}
& \mathrm{CH}:=2984 \mathrm{~cm}^{-1} \text { and CD }:=2240 \mathrm{~cm}^{-1} \mathrm{in} \\
& \mathrm{CH}:=3080 \mathrm{~cm}^{-1} \text { and } \mathrm{CD}:=2325 \mathrm{~cm}^{-1} \text {. }
\end{aligned}
$$

An approximate estimate of the bond strength, using elementary vibration theory, gives a greater value for deuterium than for light hydrogen in these compounds.

We intend to discuss these new results further elsewhere in conjunction with earlier polarisation measurements ${ }^{2}$.

\section{Geophysical Institute, Bergens Museum, Bergen. March 26.}

${ }^{1}$ K. W, F. Kohlrausch, "Smekal-Ramanefiekt",

2 B. Trumpy, Z. Phys., 90, 133: 1934. 93, 624: 1935

\section{X-Ray Study of Recovery and Recrystallisation of Aluminium Single Crystals}

To study recovery and recrystallisation after de. formation, we have adapted the rotation method of crystal analysis with flat films placed in front of and behind the specimen.

The aluminium single crystals were deformed by extension by 5-16 per cent. It is well known

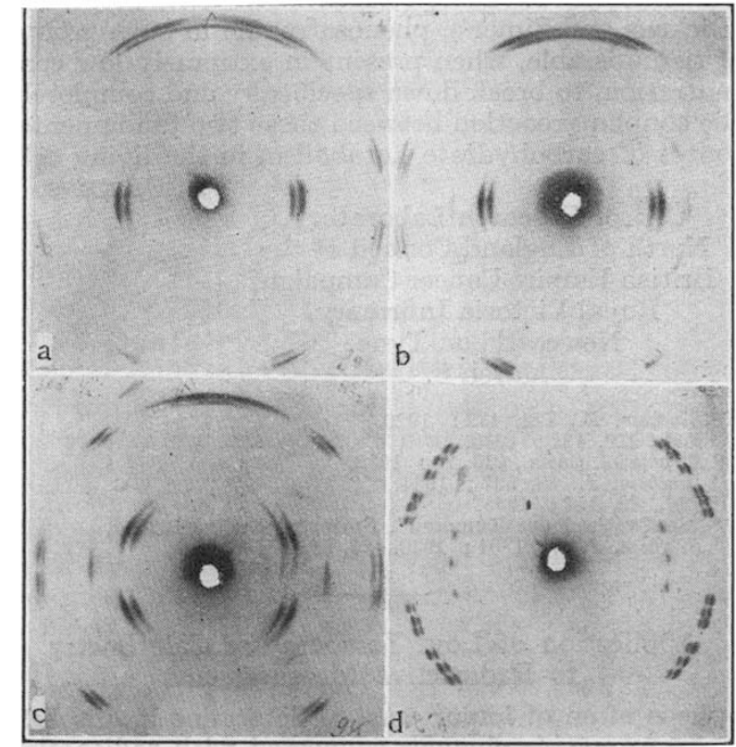

Fig. 1. X-ray analysis of single crystals of aluminium. (a) Deformation texture and (b) recovery after 2 hours at $300^{\circ}$ (c) Deformation texture and $(d)$ texture after recrystallisation.

that the asterism in the process of recovery does not change. Distinct changes in the distribution of intensity among the spots, sometimes accompanied either by their shortening or elongation, with simultaneous increase in their sharpness could be seen on some elongated spots on the $\mathrm{X}$-ray pictures taken by back reflection (see Fig. $1, a$ and $b$ ).

We consider this phenomenon to be the result of the removal of stresses and straightening of the elastically bent separate parts of the deformed single crystal. 